\title{
Screening of developmental dysplasia of the hip in the newborns
}

\author{
Bashar Sh. Mustafa, Mohamad Ah. Jasim \\ College of pharmacy, University of Mosul, Iraq
}

\begin{abstract}
Background: Newborn babies are known to have risk for occurrence developmental dysplasia of the hip so early clinical screening test is very important to detect this problem and prevent further abnormal growth. The aim of this study is to find the rate of occurrence of developmental dysplasia of the hip (DDH) among newborn babies and establish good screening program.
\end{abstract}

Patients and methods: From August $r \ldots r$ to March $r \ldots q$ in AL-Khansaa Maternity and Children Teaching hospitals, $909 r$ newborn babies were examined clinically using Barlows and ortolani tests for detecting DDH.

Results: Only $17 r$ newborn babies out of $909 \mathrm{r}$ examined babies had DDH and it was found more common among female and more on left side than right side. Female sex, rural residence, first born baby breach, caesarean section positive family history, multiple pregnancy post-mature babies, high birth weight $(>r \circ \cdots \mathrm{g})$.

Conclusion: The occurrence of neonatal DDH is still form a major problem among newborn babies causing a lot of morbidity need to follow up to avoid further complicating problem.

Keywords: DDH, newborn .

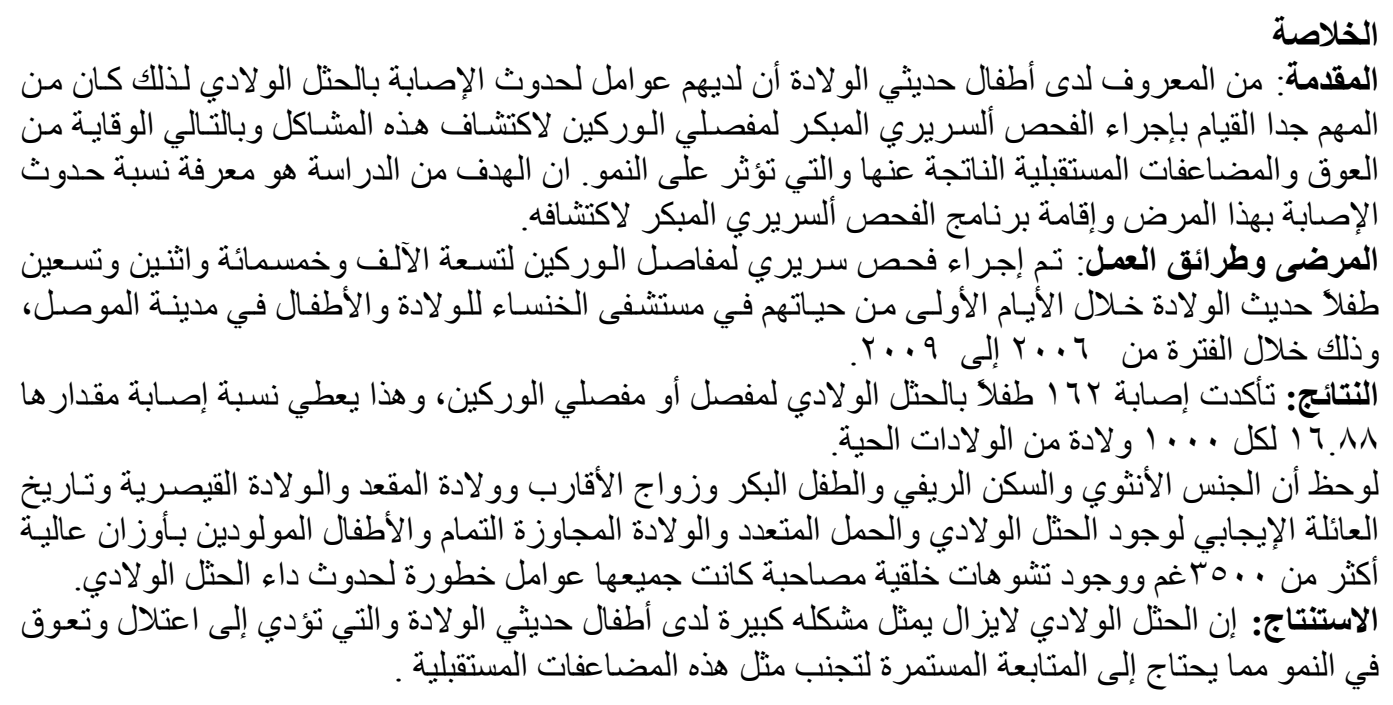

$\mathrm{D}$

evelopmental dysplasia of the hip (DDH) is an abnormal formation of the hip joint occurring between organogenesis and maturity as a result of instability'. It occurs usually in the neonatal period, dislocations tend to occur after delivery, and thus are postnatal in origin, although the exact time when dislocations occur is controversial $^{r}$. The term DDH is now used instead of congenital dislocation 
of hip $(\mathrm{CDH})^{r}$, since they are not truly congenital in origin.

Developmental dysplasia of the hip is classified into two major groups:

Typical in a neurologically normal infant

Teratologic in which there is an underlying neuromuscular disorder, such as myelodysplasia, arthrogryposis multiplex congenita or a syndrome complex ${ }^{r}$.

Teratologic dislocation occurs in utero and is therefore congenital, in which the hip is fixed in the dislocated position at birth .

A typical dislocation occurs in an otherwise healthy infant and may occur in utero, at birth or after birth ${ }^{\circ}$.

Developmental dysplasia of the hip includes hips that are unstable, malformed, sublaxated or dislocated. "

In $19 r \cdot s$, an extensive programme of early diagnosis and treatment of DDH done, while in 1904 an extensive neonatal hip surveys were begun in USA, Sweden and Britain. Very early diagnosis in these centres has resulted in simple, safe and effective treatment, and led to excellent results ${ }^{\gamma}$.

The causes of DDH are multifactorial, which include genetic factors, physiological, mechanical, postnatal factors and other risk ${ }^{\wedge}$ factors.

\section{Clinical screening}

The purpose of screening programs is to diagnose dislocation at early age when treatment is easy and the prognosis is excellent ${ }^{\vee}$, also to prevent pain, limitation of function and disability due to dislocated or subluxated hips ${ }^{9}$.

Ortolani/Barlow's maneuvers are the only currently acceptable nontraumatic procedures which do not unduly expose all children to routine irradiation '. The Ortolani / Barlow's tests are $1 \ldots \%$ specific but only $7 . \%$ sensitive in expert hands '.

\section{Patients and methods}

Nine thousand five hundred and ninety two newborn babies out of were examined clinically (in patients) for the presence of any sign of DDH in AlKhansaa Maternity and Children Teaching Hospitals during the period from the 'st of August $r \ldots r$ to the March Y...?.

Detailed information were taken from their mothers or any near relative including:

1. General information: Sex, date of birth, residence, age.

r. Maternal information: Mother's age, birth order, parental consanguinity, intrauterine presentation and type of delivery.

$r$. Family history of DDH.

£. Neonatal information: Multiple pregnancy, gestational age and birth weight.

- Presence of other congenital anomalies.

7. Presence of asymmetry in skin thigh creases and inguinal skin folds.

All these examined cases came from Mosul city and its vicinity.

Teratological and neuromuscular cases were excluded. 


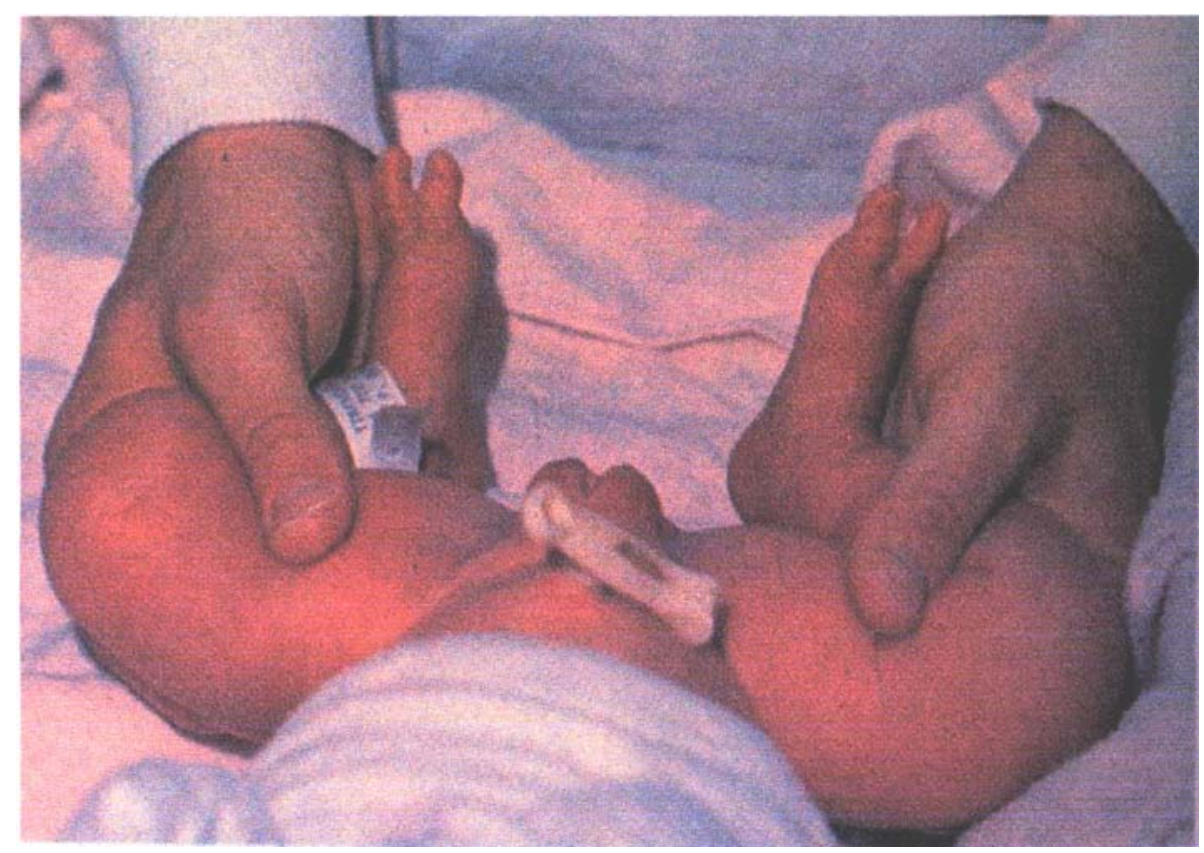

Figure 1. Ortolani test

The clinical examination consisted of the following maneuver: Ortolani (reduction) test: to detect dislocated hip, with the newborn relaxed and content on a firm surface the hips and knees are flexed to 9.0 , the hips are examined once at a time, then grasping the newborn thigh with the middle finger over the greater trochanter and lifts the thigh to bring the femoral head from its dislocated posterior position to reducing the femoral head into the acetabulum. In a positive finding, examiner senses

reduction by a palpable and nearly audible clunk (Figure ').

Barlow (dislocation) test: to detect dislocatable hips.
This test was also carried as the following:

After placing the baby on his/her back with the leg pointing towards the examiner, the hips are flexed to a right angle and the knees are fully flexed. The finger applied to the greater trochanter and the thumb of each hand is applied to the inner side of the thigh opposite to the position of the lesser trochanter as shown in (Figure $r$ ). Then the newborn thigh is adducted with a gentle downward pressure (posterior force). If the hip is dislocatable this usually readily felt as femoral head slips out of the acetabulum. After release of posterior pressure the hip will usually relocate spontaneously. 


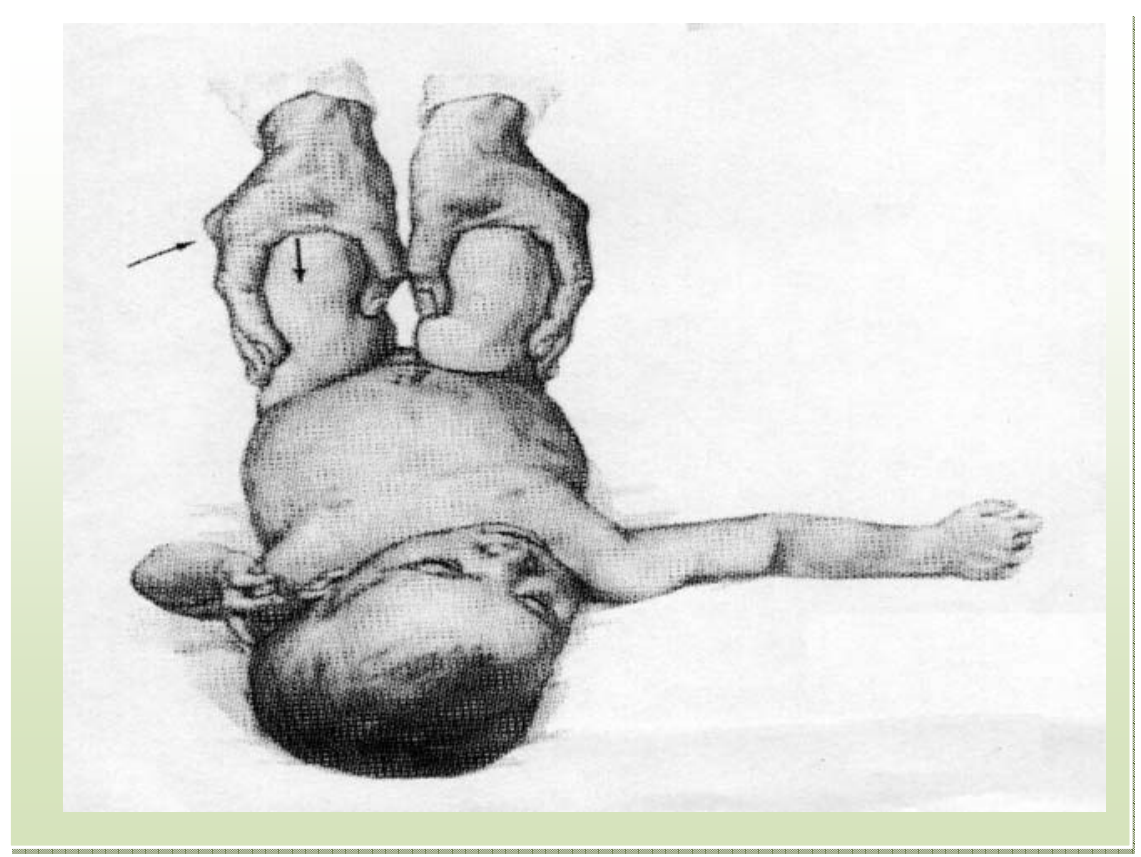

Figure $^{r}$. Barlow's test ${ }^{\prime r}$

The results were analyzed statistically by using Chi-square $\left(\chi^{r}\right)$ test, Odd's ratio and Confidence Interval (C.I.) for the Odd's ratio. $\mathrm{P}$ value less than..$\circ$ was considered significant.

\section{Results}

One hundred and sixty two newborn babies out of the examined $909 \mathrm{r}$ proved to have DDH in one or both hip joints during the first few hours after birth forming a rate of $17.9 / 1 \cdots$ live births.

Table '. Sex distribution of neonatal DDH cases and control

\begin{tabular}{|c|c|c|c|c|}
\hline \multirow{2}{*}{ Sex } & \multicolumn{2}{|c|}{ Cases } & \multicolumn{2}{c|}{ Control } \\
\cline { 2 - 5 } & No. & $\%$ & No. & $\%$ \\
\hline Female & Irr & vo & 107 & $\varepsilon \wedge$ \\
\hline Male & $\varepsilon$ & ro & $17 \Lambda$ & or \\
\hline Total & $17 r$ & $1 \ldots$ & rY & $1 \ldots$ \\
\hline
\end{tabular}

$\mathrm{P}$-Value is signifigant.

Table I shows that the majority of the cases were female ( $\vee 0 \%$ ) with a female to male ratio of $r:$ ! . 
Table $r$. Residence of neonatal DDH cases and control

\begin{tabular}{|c|c|c|c|c|}
\hline \multirow{2}{*}{ Residence } & \multicolumn{2}{|c|}{ Cases } & \multicolumn{2}{|c|}{ Control } \\
\hline & No. & $\%$ & No. & $\%$ \\
\hline Rural & 07 & ro & $7 \varepsilon$ & r. \\
\hline Urban & 1.7 & 70 & Yr. & ᄉ. \\
\hline Total & 174 & $1 \ldots$ & TrS & $1 \ldots$ \\
\hline
\end{tabular}

Table $r$ shows that a highly significant a good number of patients came from difference between cases and control in rural areas $\left(\mathrm{OR}=\mathrm{r} .{ }^{\prime}\right)$. their residence $(\mathrm{P}$ value $\leq . \cdots$ ) ) were

Table $r$. Distribution of neonatal DDH cases and control according to birth order

\begin{tabular}{|c|c|c|c|c|c|c|c|}
\hline \multirow{2}{*}{$\begin{array}{l}\text { Birth } \\
\text { order }\end{array}$} & \multicolumn{2}{|c|}{ Cases } & \multicolumn{2}{|c|}{ Control } & \multirow{2}{*}{ P-value } & \multirow{2}{*}{ OR } & \multirow{2}{*}{ C.I of OR } \\
\hline & No. & $\%$ & No. & $\%$ & & & \\
\hline 1 & ov & ro & $7 r$ & 19 & $\leq \cdot \cdots 1$ & $r . r$ & $1.01-r .0$. \\
\hline r & $r$. & 11.0 & $\leqslant 7$ & $1 \leq$ & N.S & $1 . r$ & $\cdot . \wedge 7-1.9 V$ \\
\hline$\geq r$ & Vo & $\leqslant 7.0$ & 417 & $7 V$ & $\leq \cdot \cdots 1$ & $\cdot \leqslant r$ & $\cdot . r q-\cdot . T r$ \\
\hline Total & 174 & $1 \ldots$ & rrs & $1 \ldots$ & & & \\
\hline
\end{tabular}

Overall $\chi^{r}=r \cdot .1 r \circ, \mathrm{df}=r, \mathrm{P} \leq \cdot \cdots \cdot$

From Table $r$, it is clear that the first born baby is affected more than the significant difference $(\mathrm{P}-$ value $\leq . \cdots$ ) subsequent babies with a highly and $\mathrm{OR}=r . r$ for the first born baby).

Table «. Parental consanguinity in neonatal DDH cases and control

\begin{tabular}{|c|c|c|c|c|}
\hline \multirow{2}{*}{$\begin{array}{c}\text { Parental } \\
\text { consanguinity }\end{array}$} & \multicolumn{2}{|c|}{ Cases } & \multicolumn{2}{|c|}{ Control } \\
\hline & No. & $\%$ & No. & $\%$ \\
\hline Present & NI & 0. & 10. & $\leqslant 7 . r$ \\
\hline Absent & NI & 0. & $I V \varepsilon$ & or.y \\
\hline Total & 174 & $1 \ldots$ & TYE & $1 \ldots$ \\
\hline
\end{tabular}

$$
\chi^{p}=\cdot .09, \mathrm{df}=1, \mathrm{P}=\cdot . \varepsilon \varepsilon 1, \mathrm{OR}=1.17, \mathrm{C} . \mathrm{I}=\cdot . \wedge \cdot-1.79
$$

Ttable \& shows that consanguineous marriage is a risk for the occurrence of $\mathrm{DDH}(\mathrm{OR}=1.17)$ although there is no significant difference between cases and control in the frequency of parental consanguinity. 
Table ${ }^{\circ}$. Intrauterine presentation of neonatal DDH cases and control

\begin{tabular}{|c|c|c|c|c|}
\hline \multirow{2}{*}{$\begin{array}{l}\text { Intrauterine } \\
\text { presentation }\end{array}$} & \multicolumn{2}{|c|}{ Cases } & \multicolumn{2}{|c|}{ Control } \\
\hline & No. & $\%$ & No. & $\%$ \\
\hline Breech & $\pi$ & $\wedge$ & IT & r.V \\
\hline Non-breech & $1 \leqslant 9$ & 94 & TIT & 97.1 \\
\hline Total & $17 Y$ & $1 \ldots$ & TYE & $1 \ldots$ \\
\hline
\end{tabular}

$\chi^{r}=\varepsilon .1 r, \mathrm{df}=1, \mathrm{P}=\cdot . \cdot \varepsilon, \mathrm{OR}=r . r, \mathrm{C} . \mathrm{I}=1 . \cdot r-\varepsilon . \nu \cdot$

Table $\bullet$ shows that breech presentation difference $(P$-value $=\cdot \cdot\llcorner, \mathrm{OR}=r . r)$ is a risk factor with a significant between cases and control.

Table 7 . Type of delivery of neonatal DDH cases and control

\begin{tabular}{|c|c|c|c|c|}
\hline \multirow{2}{*}{ Type of delivery } & \multicolumn{2}{|c|}{ Cases } & \multicolumn{2}{|c|}{ Control } \\
\hline & No. & $\%$ & No. & $\%$ \\
\hline Caesarean section & M & 19 & $\sum r$ & $\pi$ \\
\hline Vaginal delivery & 14 & $\wedge$ & YAY & AV \\
\hline Total & 174 & $1 \ldots$ & TrE & $1 \ldots$ \\
\hline
\end{tabular}

$\chi^{r}=r . r r, \mathrm{df}=1, \mathrm{P}=\cdot \cdot \vee r r, \mathrm{OR}=1.7, \mathrm{C} . \mathrm{I}=\cdot .97-r .7 V$

Table 7 shows no significant while the OR seems to be operational difference between cases and control, in the causation of DDH $(\mathrm{OR}=1,7)$.

Table $\vee$. Family history of neonatal DDH cases and control

\begin{tabular}{|c|c|c|c|c|}
\hline \multirow{2}{*}{ Family history } & \multicolumn{2}{|c|}{ Cases } & \multicolumn{2}{|c|}{ Control } \\
\hline & No. & $\%$ & No. & $\%$ \\
\hline Present & $\varepsilon r$ & YT & $r \cdot$ & 7 \\
\hline Absent & 119 & $V \varepsilon$ & $r \cdot \varepsilon$ & $9 \varepsilon$ \\
\hline Total & 174 & $1 \ldots$ & TYS & $1 \ldots$ \\
\hline
\end{tabular}

Table $V$ shows that $r$ r\% of cases had a family history of DDH compared to $7 \%$ of the control group with a highly significant difference ( $\mathrm{P}$ $\leq \cdot \cdots \cdot, \mathrm{OR}=0 . \varepsilon)$. 
Table ${ }^{\wedge}$. The association of multiple pregnancy with DDH

\begin{tabular}{|c|c|c|c|c|}
\hline \multirow{2}{*}{$\begin{array}{c}\text { Multiple } \\
\text { pregnancy }\end{array}$} & \multicolumn{2}{|c|}{ Cases } & \multicolumn{2}{|c|}{ Control } \\
\hline & No. & $\%$ & No. & $\%$ \\
\hline Present & 9 & 0.0 & $r$ & .7 \\
\hline Absent & 104 & $9 \leqslant 0$ & TYY & 99.2 \\
\hline Total & 174 & $1 \ldots$ & TrE & $1 \ldots$ \\
\hline
\end{tabular}

Table $\wedge$ shows that multiple pregnancy $\left.\quad \operatorname{DDH}\left(\mathrm{P}=\cdot \cdots \text {, } \mathrm{OR}=\mathrm{r}^{\prime}\right)^{\prime}\right)$. is a risk factor for the occurrence of

Table ${ }^{9}$. Distribution of neonatal DDH cases and control according to the gestational age

\begin{tabular}{|c|c|c|c|c|c|c|c|}
\hline \multirow{2}{*}{$\begin{array}{c}\text { Gestational } \\
\text { age }\end{array}$} & \multicolumn{2}{|c|}{ Cases } & \multicolumn{2}{|c|}{ Control } & \multirow{2}{*}{ P-value } & \multirow{2}{*}{ OR } & \multirow{2}{*}{ C.I } \\
\hline & No. & $\%$ & No. & $\%$ & & & \\
\hline Full-term & $10 \leqslant$ & 90 & $r \cdot \tau$ & $9 \leq .5$ & N.S & 1.1 & $.0 V-Y . I Y$ \\
\hline Pre-term & $r$ & 1.1 & $1 \leq$ & $\varepsilon . r$ & N.S & $\because \varepsilon$ & $.11-1 . \leq 0$ \\
\hline Post-term & 0 & $r . r$ & $\varepsilon$ & $1 . r$ & N.S & Y.o & $\because \vee l-\wedge . \wedge$. \\
\hline Total & 174 & $1 \ldots$ & TrE & $1 \ldots$ & & & \\
\hline
\end{tabular}

Overall $\left.\chi^{r}=r . \wedge, \mathrm{df}=r, \mathrm{P}=\cdot.\right) \leqslant r(\mathrm{~N} . \mathrm{S})$

Table ${ }^{9}$ shows no significant difference in the gestational age of DDH cases and control, but there is additional risk for post-term newborn to have $\mathrm{DDH}$ than that of preterm $\left(\mathrm{OR}=r_{.0}\right)$.

Table $1 \cdot$. Distribution of neonatal DDH cases and control according to birth weight

\begin{tabular}{|c|c|c|c|c|c|c|c|}
\hline \multirow{2}{*}{ Birth weight (gram) } & Cases & Control & P-value & OR & \multicolumn{3}{|c|}{ C.I } \\
\hline & No. & $\%$ & No. & $\%$ & & & \\
\hline$<$ < o.. & 7 & r.V & 17 & $\varepsilon .9$ & N.S & $\because V$ & $\cdot . r r-Y . I V$ \\
\hline ro.. - ro.. & 97 & $09 . r$ & rTA & AY.V & $\leq \cdot \cdots 1$ & $\cdot r$ & $\cdot r \cdot-\cdot . \leq 7$ \\
\hline$>r o .$. & 7. & TV & $\varepsilon$ & TY. & $\leq \cdot \cdots 1$ & $\varepsilon . r$ & $Y . V \cdot-7.0 \leq$ \\
\hline Total & $17 r$ & $1 \ldots$ & $T Y \Sigma$ & $1 \ldots$ & & & \\
\hline
\end{tabular}

Overall $\chi^{r}=\varepsilon \cdot r, \mathrm{df}=r, \mathrm{P} \leq \cdot \cdots \cdot$ 
Table 1. reveals that higher birth weight of the baby is effective in the causation of DDH ( P-Value $\leq$ $\because \cdots 1)$.

Table 11 . The association of congenital anomalies with neonatal DDH cases and

\begin{tabular}{|c|c|c|c|c|}
\hline \multirow{2}{*}{$\begin{array}{l}\text { Associated } \\
\text { anomalies }\end{array}$} & \multicolumn{2}{|c|}{ Cases } & \multicolumn{2}{|c|}{ Control } \\
\hline & No. & $\%$ & No. & $\%$ \\
\hline Present & 10 & $9 . Y$ & $\varepsilon$ & 1.1 \\
\hline Absent & $1 \leqslant V$ & $9 \cdot .1$ & rr. & $9 \wedge . \wedge$ \\
\hline Total & 174 & $1 \ldots$ & TY & $1 \ldots$ \\
\hline
\end{tabular}

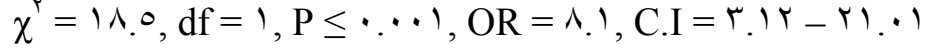

Table 11 demonstrates a highly significant $(\mathrm{P}-$ Value $\leq \cdot \cdots)$, OR $=$ ^.1) association between DDH and other congenital anomalies such as

Table Ir. Results of Ortolani test

\begin{tabular}{|c|c|c|}
\hline Ortolani test & No. & $\%$ \\
\hline Total Positive cases & 77 & $\varepsilon \cdot$ \\
\hline Total negative cases & 97 & 1. \\
\hline Total cases & $17 r$ & 1. \\
\hline
\end{tabular}

Table Ir shows that Ortolani test was positive in $\varepsilon \cdot \%$ of cases.

Table 1r. Results of Barlow's test

\begin{tabular}{|c|c|c|}
\hline Barlow's test & No. & $\%$ \\
\hline Total Positive cases & 117 & VI. \\
\hline Total negative cases & $\leqslant 7$ & Y^. $\varepsilon$ \\
\hline Total cases & $17 r$ & $1 \ldots$ \\
\hline
\end{tabular}

Table $1 \%$ shows that Barlow's test was positive in $\quad$ \. $7 \%$ of cases. congenital torticollis, metatarsus adductus, talipes calcaneovalgus and other congenital anomalies. 
Table $1 \leqslant$. The laterality distribution of neonatal DDH cases

\begin{tabular}{|c|c|c|}
\hline Laterality & Cases & $\%$ \\
\hline Left & $7 V$ & $\varepsilon 1 . \varepsilon$ \\
\hline Right & T & TY.Y \\
\hline Bilateral & 09 & r. \\
\hline Total cases & $17 r$ & $1 \ldots$ \\
\hline
\end{tabular}

Table I s shows that the left hip is more commonly involved than right hip, and bilateral involvement of the hips is also common.

Table 10. Skin thigh creases for neonatal DDH cases and controls

\begin{tabular}{|c|c|c|c|c|c|c|c|}
\hline \multirow{2}{*}{$\begin{array}{l}\text { Skin thigh } \\
\text { creases }\end{array}$} & \multicolumn{2}{|c|}{ Cases } & \multicolumn{2}{|c|}{ Control } & \multirow{2}{*}{ P-value } & \multirow{2}{*}{ OR } & \multirow{2}{*}{ C.I } \\
\hline & No. & $\%$ & No. & $\%$ & & & \\
\hline Equal & 1.7 & 70 & YOT & $v 9$ & $\leq \cdot \cdots 1$ & $\because 0$ & $\cdot r r-\cdot V \tau$ \\
\hline Unequal & $\leqslant 9$ & $r$. & rᄉ & 11.2 & $\leq \cdot \cdots 1$ & r.r & $r . \cdot V-0 . r T$ \\
\hline Inapparent & V & 0 & $r$. & $9 . r$ & $\because .0 r$ &.$\varepsilon$ & $.17-1 . .1$ \\
\hline Total & 174 & $1 \ldots$ & TrE & $1 \ldots$ & & & \\
\hline
\end{tabular}

$\left.\chi^{r}=r\right\urcorner . \wedge r, \mathrm{df}=r, P \leq \cdot \cdots r$

Table 10 demonstrates that unequal skin thigh creases were more common in the cases than in the control group
(P- value $\leq \cdot \cdots$ ). Also an evident difference is observed among those with equal and inapparent creases.

Table 17. Inguinal skin fold for neonatal DDH cases and control

\begin{tabular}{|c|c|c|c|c|}
\hline \multirow{2}{*}{ Inguinal skin folds } & \multicolumn{2}{|c|}{ Cases } & \multicolumn{2}{|c|}{ Control } \\
\hline & No. & $\%$ & No. & $\%$ \\
\hline Equal & 1.9 & $T V . Y$ & rqะ & $9 \cdot . V$ \\
\hline Unequal & or & r.^.A & $r \cdot$ & $9 . r$ \\
\hline Total & 174 & $1 \cdots$ & TYS & $1 \cdots$ \\
\hline
\end{tabular}


Table 17 shows that unequal inguinal skin folds were more common in DDH cases than in the control group (Pvalue $\leq \cdot \cdots$ l).

One hundred forty babies (^ฯ. §\%) out of I Tr came for follow-up every two weeks and at the end of one month of their age $11 \cdot(7 \wedge \%)$ of them, their hips were completely stabilized following our instructions of using double or triple nappies together with the avoidance of heavy wrapping and rolling bed. The other remaining $r$. cases $(1 \wedge .0 \%)$ were asked to come back for other follow-up for every two weeks.

\section{Discussion}

In this study, the rate of occurrence of neonatal DDH was $17.9 / 1 \ldots$ live birth, and this number are nearly similar to that reported by other studies ${ }^{1 \%-10}$. Female sex was more affected than male sex as evident by the high $\mathrm{OR}=r . r$, which means that a female sex is an effective risk factor. Female to male ratio, in this study, was $r:$ ! similar to that found by other studies ${ }^{17}$ ${ }^{1 \wedge}$, but Apley's ${ }^{19}$ found a higher ratio of $V_{:}:$.

DDH was more common in cases who came from rural areas than in the control group, a difference of highly significant value $(P \leq \cdot \cdots)$ with additional risk for rural residence among DDH cases OR $=r$. , , and this is because the incidence of DDH is influenced by geographic and ethnic factors as stated by other studies ${ }^{\Lambda_{-} r}$, however Al-Kattan ${ }^{\text {'v }}$ found no additional risk for rural residence among DDH cases.

First order baby is more prone to have DDH where the $\mathrm{OR}=r$.r in contrast to the third or more orders in the family where the OR is $\cdot . \varepsilon$. These findings $\underset{1 Q_{-} Y r}{\text { are }}$ consistent with other studies
Parental consanguinity was not significant between the cases and control although OR of 1.1 which means that probably consanguineous marriage is a risk factor similar to that found by Al-Kattan ${ }^{\text {'V }}$.

Breech presentation was a risk factor in the causation of $\mathrm{DDH}$ $(\mathrm{OR}=r, r)$. These result are $\operatorname{in}_{\Lambda_{-} r}$ agreement with other studies

also found that breech presentation and positive family history were the two most common risk factors associated with DDH. Caesarean section seems to be a risk factor for DDH where OR is 1.7 similar to that found by Al-Kattan 'V .

Family history was positive in $\varepsilon r$ cases and OR was $0 . \Sigma$ which means a high risk factor and this is probably explained by the presence of genetic factor this in agreement with other studies showed strong family history in their studies.

Multiple pregnancy was a risk factor for DDH where OR was r.', probably due to the effect of crowding phenomenon within the intrauterine cavity, A similar association was found by Al-Kattan 'Y . Post-maturity was a risk factor to have $\mathrm{DDH}\left(\mathrm{OR}=\mathrm{r} .{ }^{\circ}\right)$ while preterm delivery does not appear to predispose to $\mathrm{DDH}(\mathrm{OR}=\cdot \varepsilon)$ as Apley's ${ }^{\text {'r }}$ claimed that high level of maternal hormones in the last few weeks of pregnancy might aggravate ligamentous laxity in the infant, and this could account for the rarity of hip instability in premature babies born before the hormones reach their peak. All these findings are consistent with those previously reported ${ }^{r},{ }^{r}$.

High birth weight $>$ ro.. g seems to be effective in the causation of DDH where $\mathrm{OR}=\varepsilon . r$, while babies with low birth weigh $<$ Y. . g were protected from having $\mathrm{DDH}\left(\mathrm{OR}=\cdot{ }^{\vee}\right)$. 
This is similar to the study done by Bower et al $^{r r}$ who supported the hypothesis of intrauterine constriction as a cause of neonatal DDH. Also Beaty ${ }^{r \cdot}$ reported a low incidence of DDH in babies with low birth weight which was probably due to their premature delivery excluding them from the joint relaxing effects of maternal hormones in the last few weeks of pregnancy.

The presence of associated congenital anomalies was more common in DDH cases than in the control group where the OR was ^.), which means an increase risk of DDH among cases with associated anomalies. Beaty ${ }^{r} \cdot$ found a strong association between DDH and other musculoskeletal anomalies such as congenital torticollis, metatarsus adductus and talipes calcaneovalgus, but Al-Kattan 'v found no significant association between DDH and other anomalies.

Ortolani test was positive in $\varepsilon \cdot \%$ of patients and Barlow's test positive in $\vee 1.7 \%$ of them, this is in agreement with other workers ${ }^{r}$.

Left-sided and bilateral hip involvement were found in $\Sigma 1 . \Sigma \%$ and ז. $₹ \%$ of patients respectively, and right hip involvement in $r$ r. r\% of patients, similar to that reported by other studies $^{r \cdot, r \xi}$. On the other hand Bower $C,^{r r}$ found that bilateral involvement was twice as common in the neonatal cases and left hip involvement more than right hip involvement in the post-neonatal cases.

Unequal skin thigh creases $(\Gamma \cdot \%)$ were more common in the cases than in the control group ( $11 . \mathrm{V \%}$ ), a difference of a highly significant value $(\mathrm{P} \leq \cdot \cdots)$. Asymmetry of the skin folds is a common clinical finding of $\mathrm{DDH}^{r r}$.

Unequal inguinal folds was found in $r$ r.^\% of the cases compared to $9 . r \%$ of the control group (P value $\leq$ $\because \cdots)$. Beaty, ${ }^{r}$ noticed that most of his DDH patients had abnormal inguinal folds and recommended that inguinal fold assessment is useful in screening methods and suggested that babies with asymmetrical inguinal folds need further evaluation.

One hundred ten babies ( $\ \wedge \%)$ had clinical stabilization of the hip joint at the age of four weeks, and this is consistent with other results ${ }^{r \varepsilon}$.

\section{Conclusions}

Developmental dysplasia of the hip is still a major problem among newborn babies causing a lot of morbidity to them. Female sex, rural residence, first born baby, parental consanguinity, breech presentation, caesarean section, positive family history, multiple pregnancy, post-mature babies, high birth weight (>ro..g) and other associated congenital anomalies are all risk factors for DDH. Left hip dysplasia was more common than bilateral hip dysplasia which was more common than right hip dysplasia.The majority of the babies ( $¥ \wedge \%)$ improved nicely at the age of one month by adoption of double or triple nappies and following our instructions.

\section{References}

1. Novacheck TF. Common orthopedic problems: Developmental dysplasia of the hip. Pediat. Clin North America. 1997; $₹ r(\varepsilon)$ : Arq_A $\leqslant$.

r. Thompson GH, Scoles PV. Bone and Joint Disorders. In: Nelson Textbook of Pediatrics. Behrman RE, Kliegman RM, Jenson HB. (eds.) 17 th ed., Philadelphia, WB. Saunders Co., $r \cdots: r \cdot V V_{-} q$.

$r$. Committee on Quality Improvement, subcommittee on Developmental Dysplasia of the Hip. Clinical practice guideline: 
early detection of developmental dysplasia of the hip. Pediatrics r...;1.0 ( ₹ pt 1):^97_..०.

$\varepsilon$. Linda M, Frederick R. Screening for Developmental Dysplasia of the Hip. American Family Physician. 1999:1-11.

- Adams JC. Articular Disorders of the Hip. In: Outline of Orthopedics $q^{9}$ th ed., Churchill Livingstone,

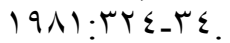

ฯ. Aronsson DD, Goldberg JM, Kling JRTF, et al. Developmental dysplasia of the hip. Pediatrics $199 \leq ; 9 \leq(r)$.

$\checkmark$. Catteral A. The early diagnosis of congenital dislocation of the hip. $\mathrm{J}$

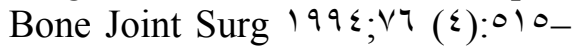
017.

^. Barr DG, Crofton PM, Goel KM. Disorders of bone, joints and connective tissue. In: Forfar and Arneil's Textbook of pediatrics. Campbell AG, Neil McIntosh (eds.), oth ed., Churchill Livingstone, 1991:10 $19-1001$.

9. Dezateux C., Godward S. A national survey of screening for congenital dislocation of the hip. Arch Dis Child 1997; $7 \leqslant(0): \leqslant \leqslant 0$ $\wedge$.

1. Paton RW. Topic for debate, at the crossroads - neonatal detection of developmental dysplasia of the hip. J Bone Joint Surg Y...; A r-B (r): 174.

11. Kessel L, Boundy U. A colour atlas of clinical orthopaedic, Regional section.Wolf Medical Publications

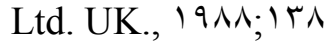

Ir. Eilert R.E., Georgopoulos G.: Orthopedics. In: Current pediatric diagnosis and treatment. William W. Hay, Anthony R., Myron J., Judith M. (eds.), I $\leqslant$ th ed., Asimon and Schuster Company, 1999;797. $\checkmark$.

1r. Danielsson LG. Instability of the hip in neonates, an ethnic and geographical study in $r \leqslant 1.1$ newborn infants in Malmo. J Bone Joint Surg Y...; ; r-B ( $\varepsilon): 0 \leqslant 0-Y$.

I ร. Bialik V, Bialik G.M, Blazers, et al. Developmental dysplasia of the hip: A new approach to incidence. Pediatrics 1999;1) ( (1):99-9.

10. Hanson G. Congenital dislocation of the hip joint: Problems in diagnosis and treatment. Current

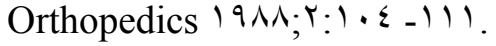

17. Lopez MJ, Navarro M.S., Martinez E. M. Echographic instability, a new concept in developmental dysplasia of the hip. J Bone Joint Surg 1990; VV-B: 199.

Iv. Al-Kattan H. Risk factors for Developmental Dysplasia of the Hip. A thesis submitted for Postgraduate study, Mosul University,,$\cdots$; ; - - l.

1^. Al-Jumaily MA. The early diagnosis of the congenital dislocation of the hip: (The need for infant screening). A thesis submitted for post graduate study, Baghdad University, $199 \cdot ;-r$.

19. Apley's GA. Regional orthopedic's hip. Apley's system of orthopedic and fractures. Vth ed., Butter Worth - Heinemann, UK., 199\%: $-\varepsilon r \cdot$

$r \cdot$. Beaty JH. Congenital and developmental anomalies of hip and pelvis. In: Canale ST., Campbells Operative Surgery. 9th ed., Mosby - Year Book, St. Louis, USA, 199A: 1.r1-1.rr.

Y.. Chan A, Mc Caul KA, Cundy PJ, et al. Perinatal risk factors for developmental dysplasia of the hip. Archives for Disease in childhood 199V; Vฯ ( $): F 9 \leq-F 1 \cdots$.

rr. Bower C, Stanley FJ, Krickfer A. Congenital dislocation of the hip in Western Australia, a comparison of neonatally and postneonatally diagnosed cases. Clin Orthop Rel.

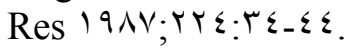

$r$. Omeroglu H, Koparal S. The role of clinical examination and risk 
factors in the diagnosis of developmental dysplasia of the hip: a prospective study in $1 \wedge \wedge$ referred young infants. Arch Othop Trauma

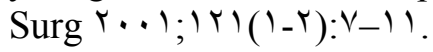

rร. Darmonov AV, Zagora S. Clinical screening for congenital dislocation of the hip. J Bone joint Surg

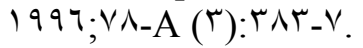

